\title{
Tekrarlı trafik yükleri altında farklı kil içeriklerine sahip orta-sıkı kum-kil karıșımlarının esneklik modülünün incelenmesi
}

\section{Investigation of resilient modulus of medium-dense sand-clay mixtures with different clay contents under repeated traffic loads}

\author{
Halil İbrahim Fedakar 1 ,*( \\ ${ }^{1}$ Abdullah Gül Üniversitesi, Inşaat Mühendisliği Bölümü, 38080, Kayseri Türkiye
}

\section{Özet}

Esneklik modülü, tekrarl trafik yükleri altında yol temel tabakalarının uzun dönem deformasyon performansinın tahmin edilmesinde yaygin olarak kullanılmaktadır. Bu nedenle, bu malzeme özelliğinin doğru tayini yol tasarımlarında büyük öneme sahiptir. Bu çalışmada, orta sıkı kum-kil karıșımlarının esneklik modülü, dinamik üç eksenli ve kalp şekli gerilme izleri ile araştırılmıştır. Bu amaç doğrultusunda, ağırlıkça \%0, \%5, \%10 ve \%20 kil içeren kum-kil numuneleri \%50 bașlangıc rölatif sıkılıkta hazırlanmış ve yarık silindir deney cihazı kullanılarak test edilmiştir. Deney sonuçlarına göre kum-kil karıșımlarının esneklik modülü değerleri dinamik üç eksenli gerilme izi ile daha fazla tahmin edilmektedir. Bu durum ise orta-sıkı kum-kil karışımlarının trafik yükleri altındaki deformasyon davranısııın kalp sekli gerilme izine kıyasla daha düsük tahmin edilmesine sebep olmaktadır. Bu çalışmanın bulgularına dayanarak, kum-kil karışımlarının esneklik modülünün yol tasarımları için daha doğru bir şekilde tahmin edilmesinde kalp şekli gerilme izinin göz önüne alınması gerektiği sonucuna varılmıştır

Anahtar kelimeler: Esneklik modülü, Kum-kil karıșımı, Kalp şekli gerilme izi, Dinamik üç eksenli gerilme izi

\section{Giriș}

Esneklik modülü $\left(M_{r}\right)$, zeminlerin dinamik yükler altındaki davranışını tanımlayan temel malzeme özelliklerinden biridir. Bundan dolayı tekrarlı trafik yüklerine maruz kalan zeminlerin deformasyon davranışını tahmin etmek için mekanik-ampirik yol tasarımlarında ana girdi parametresi olarak kullanılmaktadır. Yol temel tabakalarında (temel (base), alt temel (subbase) ve taban zemini (subgrade)) kullanılacak olan zeminlerin esneklik modülünün doğru bir şekilde belirlenmesi, daha dayanıklı ve ekonomik yol tasarımları için büyük önem arz etmektedir. Bundan dolayı zeminlerin esneklik modülünün laboratuvar deneyleri ile belirlenmesi konusu yoğun olarak çalışılmaktadır [1-7]. Yapılan bu çalışmalarda, daha çok dinamik üç eksenli deneyleri kullanılmıştır.

Zemin daneleri, hareketli tekerlek yüklerinden dolayı asal gerilme dönmelerine (principal stress rotation) maruz kalmaktadır. Bu gerilme durumu, laboratuvar ortamında kalp şekli gerilme izi (heart-shaped stress path) ile başarılı bir şekilde simüle edilebilmektedir [3, 8-11]. Ancak geleneksel dinamik üç eksenli deneyleri, trafik yüklerinden dolayı yol zemin tabakalarının maruz kaldığ simüle edememektedir $[8,12]$. Bu nedenle kalp şekli gerilme izi gibi kompleks gerilme izini laboratuvar ortamında simüle etmek için daha gelişmiş deney sistemlerine ihtiyaç

\begin{abstract}
Resilient modulus is commonly used in prediction of long-term deformation performances of pavement foundation layers under repeated traffic loads. For this reason, the determination of this material property accurately has a great importance in pavement designs. In this study, resilient modulus of medium-dense sand-clay mixtures was investigated through cyclic triaxial and heart-shaped stress paths. For this purpose, sand-clay specimens having a clay content as 0\%, 5\%, 10\%, and $20 \%$ by weight were prepared at an initial relative density of $50 \%$ and tested using hollow cylinder testing apparatus. According to the test results, the resilient modulus values of sand-clay mixtures are overestimated by cyclic triaxial stress path, which results in the underestimation of deformation behavior of medium-dense sand-clay mixtures under traffic loads compared to heart-shaped stress path. Based on the findings of this study, it is concluded that a heart-shaped stress path should be taken into consideration for a more accurate prediction of resilient modulus of sandclay mixtures for pavement designs.
\end{abstract}

Keywords: Resilient modulus, Sand-clay mixture, Heart-shaped stress path, Cyclic triaxial stress path

duyulmaktadır. Yarık silindir deneyi (hollow cylinder test), bu amaç için başarılı bir şekilde uygulanan deneylerdendir [3, 8-14]. Kalp şekli gerilme izi ile yapılan çalışmalara göre zeminlerin trafik yükleri altındaki deformasyon davranışı geleneksel üç eksenli gerilme izi ile daha düşük tahmin edilmektedir.

Zeminlerin esneklik modülü, su içeriği ve maruz kalınan gerilme durumlarının yanı sıra zemin türüne bağlı olarak da değişmektedir. Yumuşak ince daneli zeminler, dinamik yükler altında yüksek sıkışma ve deformasyon davranışı gösterdiği için yol uygulamalarında daha çok iri daneli zeminler kullanılmaktadır. Ancak doğal zeminler genellikle iri ve ince daneli zeminlerin karışımından oluşmaktadır. Bundan dolayı kum-kil karışımlarının mühendislik özellikleri yoğun olarak araştırılmaktadır [15-19]. Farklı oranlarda kil içeren kum-kil karışımları üzerine yapılan çalışmalarda, kumun taşıma kapasitesi, hidrolik geçirgenlik ve deformasyon davranışı gibi mühendislik özelliklerinin kil içeriğine bağlı olarak değiştiği görülmüştür. Simpson ve Evans [15]'a göre kum-kil karıșımları için kritik bir kil içeriği bulunmaktadır. Bu kritik kil içeriğinde, kum daneleri deplasman yaşamadan kum-kil karışımlarında minimum boşluk oranı meydana gelmektedir. Böylelikle kritik kil içeriğine kadar kil içeren kum-kil karışımlarında yük altında daha çok iri daneli zeminin davranışı hakim olmaktadır [15].

\footnotetext{
* Sorumlu yazar / Corresponding author, e-posta / e-mail: halilibrahim.fedakar@agu.edu.tr (H. İ. Fedakar) Geliș / Recieved: 21.11.2020 Kabul / Accepted: 05.01.2021 Yayımlanma / Published: 15.01.2021 doi: $10.28948 /$ ngmuh.829513
} 
Bundan dolayı düşük oranlarda kil içeren kum-kil karışımları da yol uygulamalarında kullanılmaktadır.

Düşük rölatif sıkılığa $\left(D_{r}\right)$ sahip zeminler yük altında daha fazla deformasyon davranışı sergilemektedir. Bundan dolayı taşıma gücünü artırmak ve deformasyon davranışını iyileştirmek için zemin tabakaları yol mühendisliğ uygulamalarında daha yüksek rölatif sıkılıkta sıkıştırılmaktadır. Ancak uygulanan bu kompaksiyon enerjisinin zemin tabakalarının rölatif sıkılık değerine etkisi derinlikle azalmaktadır [20]. Bundan dolayı artan derinliklerde daha az rölatif sıkılık değeri elde edilmektedir.

Literatür araştırmasına göre düşük miktarlarda kil içeren orta-sıkı kum-kil karışımlarının esneklik modülü kalp şekli gerilme izi ile araştırılmamıştır. Bu çalışmanın amacı, saha şartlarında asal gerilme dönmesine maruz kalan orta-sıkı kum-kil karışımlarının esneklik modülünün dinamik üç eksenli ve yarık silindir deneyleri ile daha doğru bir şekilde belirlenmesidir. Dinamik üç eksenli deneyleri ile, kum-kil numuneleri sadece tekrarlı eksenel gerilmeye (cyclic axial stress, $\sigma_{z}^{c y c}$ ) maruz kalmaktadır. Diğer yandan kalp şekli gerilme izini laboratuvar ortamında simüle edebilmek için tekrarlı eksenel gerilmenin yanı sira burulmalı kayma gerilmesi (torsional shear stress, $\tau_{z \theta}$ ) de yarık silindir deneyleri ile kum-kil numunelerine uygulanmıştır. Elde edilen dinamik üç eksenli ve yarık silindir deney sonuçları asal gerilme dönmelerinin zeminlerin esneklik modülüne etkilerini daha iyi tanımlayabilmek için birbirleri ile karşılaştırılmıştır.

\section{Materyal ve metot}

\subsection{Malzemeler}

Bu çalışmada, Ottawa kumu ve kaolin kili kullanılmıştır. $\mathrm{Bu}$ zeminlere ait dane çapı dağılımları Şekil 1'de sunulmuştur. Ayrıca bu zeminlerin bazı mühendislik özellikleri de Tablo 1'de verilmiştir. Tablo 1'deki bilgilere göre bu çalışmada kullanılan iri daneli ve ince daneli zeminler Birleştirilmiş Zemin Sınıflandırma Sistemi (USCS)'ne göre sırası ile kötü derecelenmiş kum (SP) ve yüksek plastisiteli kil $(\mathrm{CH})$ olarak sınıflandırılmıştır.

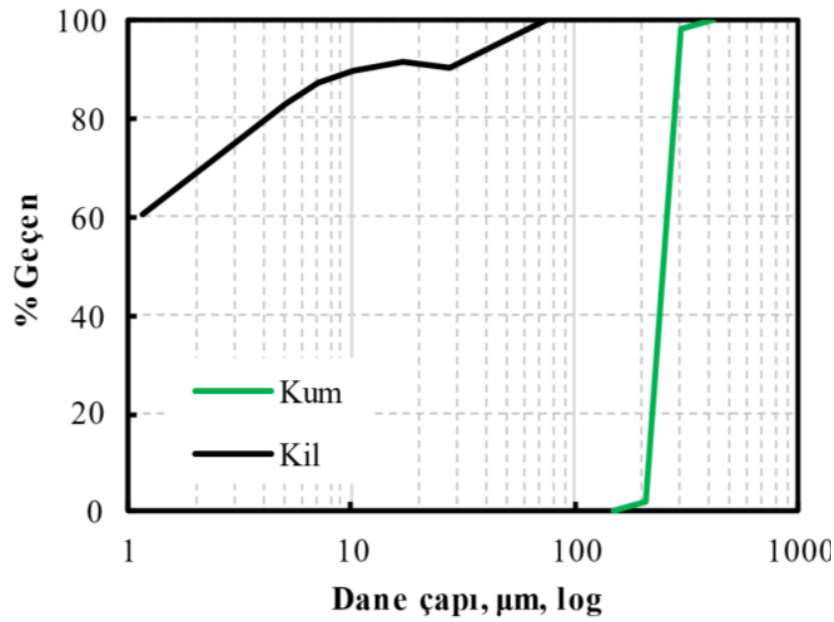

Şekil $1 \mathrm{Bu}$ çalışmada kullanılan zeminlerin dane çapı dağılımları
Tablo 1. Zeminlerin bazı mühendislik özellikleri

\begin{tabular}{lcc}
\hline Mühendislik Özellikleri & Kum & Kil \\
\hline Eğrilik katsayısı $\left(C_{c}\right)$ & 0.97 & - \\
Üniformluk katsayısı $\left(C_{u}\right)$ & 1.22 & - \\
Maksimum boşluk oranı $\left(e_{\text {maks }}\right)$ & 0.78 & - \\
Minimum boşluk oranı $\left(e_{\text {min }}\right)$ & 0.61 & - \\
Likit limit $(L L)(\%)$ & - & 62 \\
Plastik limit $(P L)(\%)$ & - & 41 \\
Özgül ağırlık $\left(G_{s}\right)$ & 2.65 & 2.65 \\
\hline
\end{tabular}

\subsection{Numune hazırlama ve deney prosedürleri}

Bu çalışmada kullanılacak olan kil içeriğini belirlemek için ağırlıç̧a $\% 0, \% 5, \% 10, \% 20$ ve $\% 30$ oranlarında kil içeren kum-kil karışımlarının minimum boşluk oranları siras 1 ile $0.61,0.60,0.55,0.53$ ve 0.66 olarak belirlenmiştir. Bu sonuçlara dayanarak bu çalışmadaki kritik kil içeriği \%20 olarak belirlenmiştir. Bundan dolayı düşük kil içeriğine sahip kum-kil karışımlarını temsil etmek için bu çalışmada ağırlıç̧a $\% 0, \% 5, \% 10$ ve $\% 20$ kil içeren kum-kil numuneleri hazırlanmıştır. Hazırlanan bütün numuneler yarık silindir şeklinde olup $200 \mathrm{~mm}$ yüksekliğe, $100 \mathrm{~mm}$ dış çapa ve $60 \mathrm{~mm}$ iç çapa sahiptir. Deneye tabi tutulacak kumkil karışımları önceden belirlenen oranlarda kuru olarak bir kap içerisinde dikkatlice karıştırılarak elde edilmiştir. Elde edilen bu karışımlar kuru çökelme (dry deposition) yöntemi ile yarık silindir şeklindeki deney kalıplarına huni kullanarak önceden belirlenen miktarlarda on tabaka olarak dökülmüş ve bu tabakalar her bir numune $\% 50$ başlangıç rölatif sıkılık değerine sahip olacak şekilde tokmak yardımıyla sıkıştırılmıştır.

Bir sonraki aşamada, numunelerin dik durabilmesi için vakum basıncı $(20 \mathrm{kPa})$ uygulanmış ve numuneler yarık silindir deney sistemine yerleştirilmiştir. İç ve dış hücreler havası alınmış saf su ile doldurulduktan sonra numunelere iç (inner) ve dış (outer) hücre basınçları $\left(\begin{array}{lll}30 & \mathrm{kPa}\end{array}\right)$ uygulanmıştır. Hücre basınçlarından hemen sonra numuneye uygulanan vakum basıncı salıverilmiştir. Bu aşamadan sonra numunelerin içerisindeki havayı çıkartmak için havası alınmış saf su numunenin içerisinde aşağıdan yukarıya doğru dolaştırılmıştır. Numunelerin içerisindeki hava çıkarıldıktan sonra iç ve dış hücre basınçları ve geri basıncı kademeli olarak sırasıyla $320 \mathrm{kPa}$ ve $300 \mathrm{kPa}$ değerlerine artırılmıştır. $\mathrm{Bu}$ basınç değerlerinde numunelerin suya doyurma işlemi gerçekleştirilmiştir. Numunelerin suya doygunluğu ise Skempton'ın $B$ katsayısına göre belirlenmiştir. Suya doyurma işleminden sonra bütün numuneler 0.95 'ten daha yüksek $B$ değerleri vermiştir. Bu durum uygulanan basınçlar altında numunelerin suya doygun hale geldiğini göstermektedir. Suya doyurma işleminden sonra numuneler konsolidasyon işlemine tabi tutulmuştur. $\mathrm{Bu}$ aşamada uygulanan geri basıncı sabit tutulurken, eksenel gerilme ve iç/dış hücre basınçları kademeli olarak sırasıyla $360 \mathrm{kPa}$ ve $330 \mathrm{kPa}$ değerlerine artırılmış ve numuneler bu basınç değerlerinde anizotropik olarak $\left(K_{o}=0.5\right)$ konsolide edilmiştir. Konsolidasyon aşamasının hemen sonrasında numuneler Tablo 2'de belirtilen deney programına uygun olarak dinamik eksenel gerilme ve burulmalı kayma gerilmelerine maruz bırakılmıştır.

Trafik yükünün gerçek frekansı $0.5 \mathrm{~Hz}$ ile $5 \mathrm{~Hz}$ arasında değişmektedir [10]. Bundan dolayı trafik yükünü simüle 
etmek için bu çalışmadaki numuneler $1 \mathrm{~Hz}$ yükleme frekansına tabi tutulmuştur [3, 12, 21]. Ayrıca tekrarl yüklemeye maruz kalan zeminlerde meydana gelen toplam deformasyon gelişiminin büyük bir kısmı ilk 1000 tekrarlı yükleme sayısında gerçekleşmektedir [11-13]. Bu nedenle kum-kil numuneleri bu çalışmada 5000 tekrarlı yüklemeye maruz bırakılmıştır.

Tablo 2. Deney programı

\begin{tabular}{lcccc}
\hline Deney & Kum $(\%)$ & Kil $(\%)$ & $\sigma_{z}^{c y c}(\mathrm{kPa})$ & $\tau_{z \theta}^{c y c}(\mathrm{kPa})$ \\
\hline \multirow{4}{*}{ Üç eksenli } & 100 & 0 & & \\
& 95 & 5 & 12 & 0 \\
& 90 & 10 & & \\
& 80 & 20 & & \\
Yarık silindir & 100 & 0 & & 4 \\
& 95 & 5 & \multirow{2}{*}{12} & \\
\hline
\end{tabular}

\subsection{Kalp şekli gerilme izi}

Yukarıda da bahsedildiği üzere hareketli tekerlek yükünden dolayı yol zemin tabakaları asal gerilme dönmelerine maruz kalmaktadır. Böylesi gerilme durumu ise kalp şekli gerilme izi ile başarılı bir şekilde simüle edilebilmektedir. Bir kalp şekli gerilme izi deviatorik gerilme uzayında $\left(\tau_{z \theta}\right.$ vs $\left(\sigma_{z}-\sigma_{\theta}\right) / 2, \sigma_{\theta}$ : çevresel gerilme (Denklem (1)), eksenel gerilme $\left(\sigma_{z}\right)$ ve burulmalı kayma gerilmesinden $\left(\tau_{z}\right)$ oluşmaktadır. Denklem (1)'deki $p_{o}, p_{i}, r_{o}$ ve $r_{i}$, sırasıyla dış hücre basıncı, iç hücre basıncı, diş yarıçap ve iç yarıçapı temsil etmektedir. Gerilme dalgaformlarının ve kalp şekli gerilme izinin tipik örneği ise Şekil 2'de gösterilmiştir.

$$
\sigma_{\theta}=\frac{p_{o} r_{o}-p_{i} r_{i}}{\left(r_{o}-r_{i}\right)}
$$

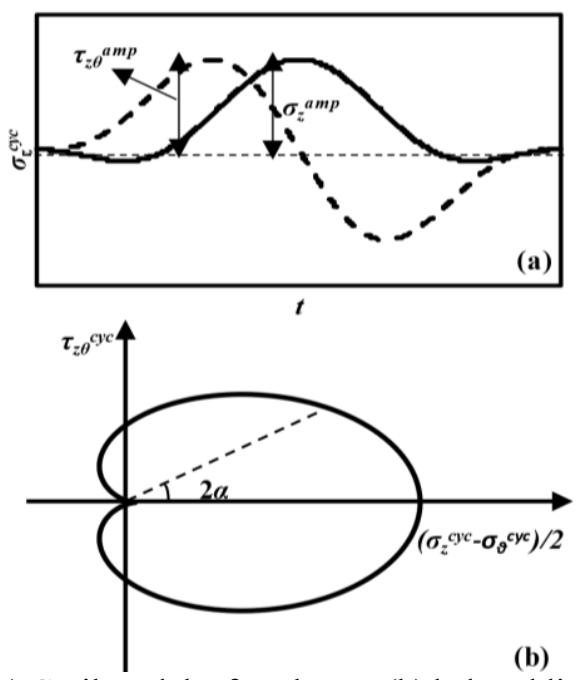

Şekil 2 (a) Gerilme dalgaformları ve (b) kalp şekli gerilme izi

Şekil 2'de gösterilen $\alpha$ ise en büyük asal gerilmenin düşey eksen ile yaptığı açıyı ifade etmektedir. Kalp şekli gerilme izi için uygulanacak olan gerilme dalgaformlarının matematiksel ifadeleri Denklem (2) ve (3)'te verilmiştir.
Denklem (2) ve (3)'te yer alan $t$ ve $T$ ifadeleri sirasiyla yükleme süresi ve periyodu ifade etmektedir.

$$
\begin{gathered}
\sigma_{z}^{c y c}=0.5 \sigma_{z}^{a m p}\left[\frac{1}{2} \cos \left(\frac{4 \pi}{T} t\right)-\cos \left(\frac{2 \pi}{T} t\right)+\frac{1}{2}\right] \\
\tau_{z \theta}^{c y c}=0.77 \tau_{z \theta}^{a m p}\left[\sin \left(\frac{2 \pi}{T} t\right)-\frac{1}{2} \sin \left(\frac{4 \pi}{T} t\right)\right]
\end{gathered}
$$

\section{Bulgular ve tartışma}

\subsection{Gerilme izi}

Tablo 2'de sunulan deney programına göre üç eksenli gerilme izini (ÜEGI) yarık silindir deney sisteminde simüle etmek için numuneler sadece tekrarlı eksenel gerilmeye maruz kalmıştır. Diğer yandan kalp şekli gerilme izini (KŞGI) simüle etmek için ise tekrarlı eksenel gerilmenin yanı sıra tekrarlı burulmalı kayma gerilmesi de kum-kil numunelerine uygulanmıştır. Uygulanan eksenel gerilme ve burulmalı kayma gerilmesine ait dalgaformlarının ve elde edilen gerilme izlerinin örnekleri Şekil 3 'te sunulmuştur.
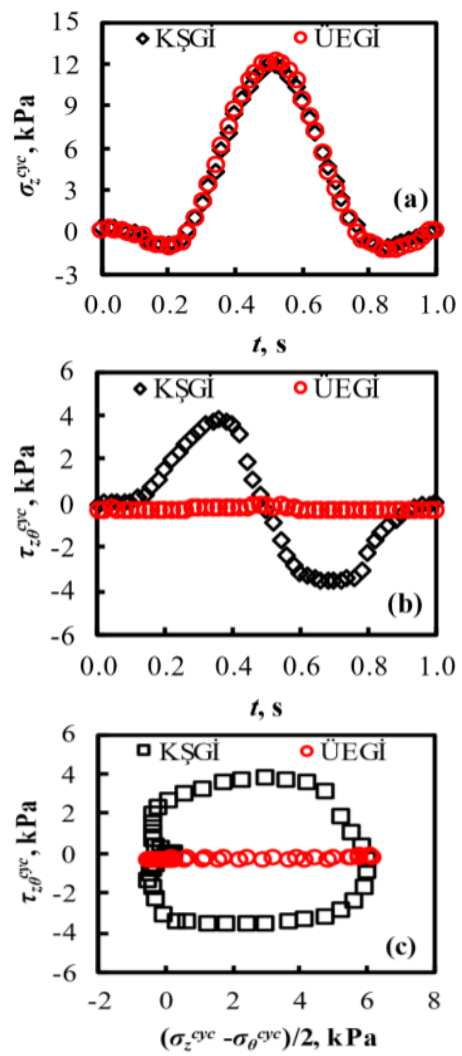

Şekil 3 Uygulanan (a) tekrarlı eksenel gerilme $\left(\sigma_{z}^{c y c}\right)$ ve (b) tekrarlı burulmalı kayma gerilmesine $\left(\tau_{z} \theta^{c y c}\right)$ ait örnek dalgaformları ve çalışmada uygulanan (c) gerilme izleri

Şekil 3'e göre Tablo 2'de belirtilen eksenel gerilme ve burulmalı kayma gerilmesine ait genlik (amplitude) değerleri üç eksenli ve yarık silindir deneylerinde başarılı bir şekilde elde edilmiştir. Ayrıca uygulanan kalp şekli ve üç eksenli gerilme izleri de bu çalışmada başarılı bir şekilde üretilmiş ve uygulanmıştır. Şekil 3 'te sunulan deney verilerine göre bu deneysel çalışmada KŞGİ ve ÜEGİ başarılı bir şekilde 
simüle edilmiştir. Bundan dolayı bu çalışmada elde edilen deney sonuçlarının kabul edilebilir bir güvenilirliğe sahip olduğu söylenebilir.

\subsection{Esneklik modülü ve şekil değiştirme davranışı}

Bu çalışmada, KŞGİ-\%20 Kil numunesi (kalp şekli gerilme izi ve \%20 kil) haricindeki diğer numuneler uzun dönemli davranışı analiz etmek için 5000 tekrarlı yüklemeye maruz bırakılmıştır. Bu numunelerde, esneklik modülünün tekrarlı yükleme sayısı ile değişimini incelemek için farklı tekrarlı yükleme sayılarında $(\mathrm{N}=10,100,1000$ ve 5000) hesaplanan esneklik modüllerinin değişimi Şekil 4'te sunulmuştur. Diğer yandan KŞGİ-\%20 Kil numunesi 478 tekrarlı yüklemede göçtüğü için $\left(\varepsilon_{z}^{p} \geq 5 \%\right)$ bu numunenin esneklik modülünün tekrarlı yükleme sayısı ile değişiminde $\mathrm{N}=10,100$ ve 478 tekrarlı yükleme sayıları kullanılmıştır (Şekil 4(d)). Guo vd. [3] yumuşak zeminler üzerinde yaptıkları yarık silindir deneylerinde esneklik modülünü $\left(M_{r}\right)$ maksimum gerilme farkının $\left(\Delta \sigma_{z}{ }^{\text {maks }}\right)$ elastik şekil değiştirmeye $\left(\varepsilon_{z}^{r}\right)$ oranı olarak tanımlamışlardır $\left(M_{r}=\Delta \sigma_{z}{ }^{\text {maks }} / \varepsilon_{z}{ }^{r}\right)$. Farklı tekrarlı yükleme sayılarında ve gerilme izlerinde kum-kil numunelerinde ölçülen maksimum eksenel gerilme farkı ve elastik eksenel şekil değiştirme değerleri Tablo 3 'te sunulmuştur. Ayrıca yukarıda belirtilen farklı tekrarlı yükleme sayılarında ölçülen elastik eksenel şekil değiştirmenin bu tekrarlı yükleme sayılarındaki toplam eksenel şekil değiştirmeye oranı $\left(\varepsilon_{z}^{r} / \varepsilon_{z}^{t}\right)$ da Tablo 3 'te verilmiştir. Esneklik modülünün farklı tekrarlı yükleme sayılarında ve gerilme izlerinde kümülatif kalıcı eksenel şekil değiştirmeye $\left(\left(\varepsilon_{z}^{p}\right)_{\text {kümülatif }}\right)$ etkisi de Şekil 5 'te gösterilmiş̧tir.

Şekil 4'te açıkça görüldüğü üzere kum zeminin esneklik modülü değerleri her iki gerilme izi (ÜEGİ ve KŞGI) altında artan kil içeriği ile azalmaktadır. Kum numunelerde, (\%0 kil) 1000 tekrarlı yüklemeye kadar esneklik modülü değerlerinde çok az bir değişim olmaktadır (Şekil 4(a)). Ancak 1000 tekrarlı yüklemeden sonra bu numunelerin esneklik modülü değerleri daha fazla azalmaktadır. Bundan dolayı kum zemin kullanan yol yapılarının daha güvenli ve ekonomik tasarımı için nihai esneklik modülü değerleri kullanılmalıdır. Kum numunelerde, KŞGİ altında daha az eksenel gerilme farkı ölçülmüştür (Tablo 3). Buna rağmen kum numune KŞGI altında daha yüksek esneklik modülü değeri vermektedir. $\mathrm{Bu}$ durum ise kum numunenin KŞGİ altında daha az elastik şekil değiştirme davranışı sergilemesinden kaynaklanmaktadır (Tablo 3). Ayrıca 1000 tekrarlı yükleme sayısından sonra esneklik modülünde meydana gelen azalma KŞGİ altında daha fazla olmaktadır. Şekil 5(a)'ya göre 1000 tekrarlı yükleme sayısından sonra KŞGI'ne maruz kalan kum zeminin esneklik modülünde meydana gelen daha fazla azalma 1000 tekrarlı yükleme sayısından sonra bu numunede daha fazla kalıcı deformasyonun gelişimine sebep olmaktadır. 1000 tekrarlı yükleme sayısına kadar ise kum zeminde farklı gerilme izlerinden dolayı meydana gelen kalıcı şekil değiştirme performansları benzer sonuçlar vermiş̧tir. 5000 tekrarlı yükleme sayısında ise kum numuneler her iki gerilme izi altında benzer esneklik modülü davranışı sergilemektedir. Şekil 4(a)'daki sonuçlara göre bu çalışmada uygulanan farklı gerilme izleri kum zeminlerin uzun dönem esneklik modülü değerlerinde benzer sonuçlar vermektedir. Buna göre kum numunelerin bu çalışmada maruz kaldıkları gerilme durumlarında asal gerilme dönmesinin esneklik modülü değerine etkisi çok az olmaktadır. Ancak Şekil 5(a)'daki sonuçlar da göz önüne alındığında kum zeminlerin esneklik modülünün belirlenmesinde KŞGİ'nin göz önüne alınması gerektiği sonucuna da varılabilmektedir. Ayrıca her iki gerilme izi altında yukarıda belirtilen tekrarlı yükleme sayılarında meydana gelen toplam şekil değiştirmenin büyük kısmını elastik şekil değiştirme oluşturmaktadır $\left(\varepsilon_{z}^{r} / \varepsilon_{z}{ }^{t}>98\right)$ (Tablo $3)$.

Tablo 3. Farklı tekrarlı yükleme sayılarında (N) ölçülen maksimum eksenel gerilme farkı $\left(\Delta \sigma_{z}^{m a k s}\right)$, elastik şekil değiştirme $\left(\varepsilon_{z}^{r}\right)$ ve elastik şekil değiştirme/toplam şekil değiştirme oranı $\left(\varepsilon_{z}^{r} / \varepsilon_{z}^{r}\right)$ sonuçları

\begin{tabular}{|c|c|c|c|c|}
\hline Numune & $\mathrm{N}$ & $\Delta \sigma_{z}^{m a k s}(\mathrm{kPa})$ & $\varepsilon_{z}^{r}(\%)$ & $\varepsilon_{z}^{r} / \varepsilon_{z}{ }^{t}(\%)$ \\
\hline \multirow{4}{*}{ ÜEGİ-\%0 } & 10 & 11.9668 & 0.00930 & 99.47 \\
\hline & 100 & 11.8826 & 0.00925 & 100.00 \\
\hline & 1000 & 11.9588 & 0.00940 & 99.47 \\
\hline & 5000 & 12.2656 & 0.00985 & 99.49 \\
\hline \multirow{4}{*}{ KŞGİ-\%0 } & 10 & 11.7947 & 0.00900 & 99.45 \\
\hline & 100 & 11.7640 & 0.00890 & 98.89 \\
\hline & 1000 & 12.1839 & 0.00930 & 100.00 \\
\hline & 5000 & 12.0878 & 0.00965 & 100.00 \\
\hline \multirow{4}{*}{ ÜEGİ-\%5 } & 10 & 11.6086 & 0.01125 & 94.14 \\
\hline & 100 & 11.8837 & 0.01140 & 99.56 \\
\hline & 1000 & 11.8762 & 0.01110 & 100.00 \\
\hline & 5000 & 11.8611 & 0.01135 & 100.00 \\
\hline \multirow{4}{*}{ KŞGİ-\%5 } & 10 & 11.3229 & 0.01090 & 88.98 \\
\hline & 100 & 11.9167 & 0.01125 & 98.25 \\
\hline & 1000 & 11.6242 & 0.01100 & 100.00 \\
\hline & 5000 & 11.5407 & 0.01145 & 99.57 \\
\hline \multirow{4}{*}{ ÜEGİ-\%10 } & 10 & 11.8961 & 0.00990 & 98.51 \\
\hline & 100 & 11.9403 & 0.01005 & 100.00 \\
\hline & 1000 & 11.9033 & 0.01015 & 99.51 \\
\hline & 5000 & 12.0937 & 0.01035 & 99.52 \\
\hline \multirow{4}{*}{ KŞGİ-\%10 } & 10 & 11.1052 & 0.01090 & 89.71 \\
\hline & 100 & 11.6148 & 0.01130 & 98.26 \\
\hline & 1000 & 11.5352 & 0.01060 & 100.00 \\
\hline & 5000 & 11.5246 & 0.01115 & 100.00 \\
\hline \multirow{4}{*}{ ÜEGİ-\%20 } & 10 & 12.2158 & 0.01225 & 93.16 \\
\hline & 100 & 12.1456 & 0.01240 & 99.20 \\
\hline & 1000 & 12.2816 & 0.01110 & 99.55 \\
\hline & 5000 & 12.5826 & 0.01080 & 99.54 \\
\hline \multirow{3}{*}{ KȘGİ- $\% 20$} & 10 & 9.7979 & 0.01020 & 30.00 \\
\hline & 100 & 10.2206 & 0.01085 & 43.14 \\
\hline & 478 & 10.2015 & 0.01135 & 65.61 \\
\hline
\end{tabular}



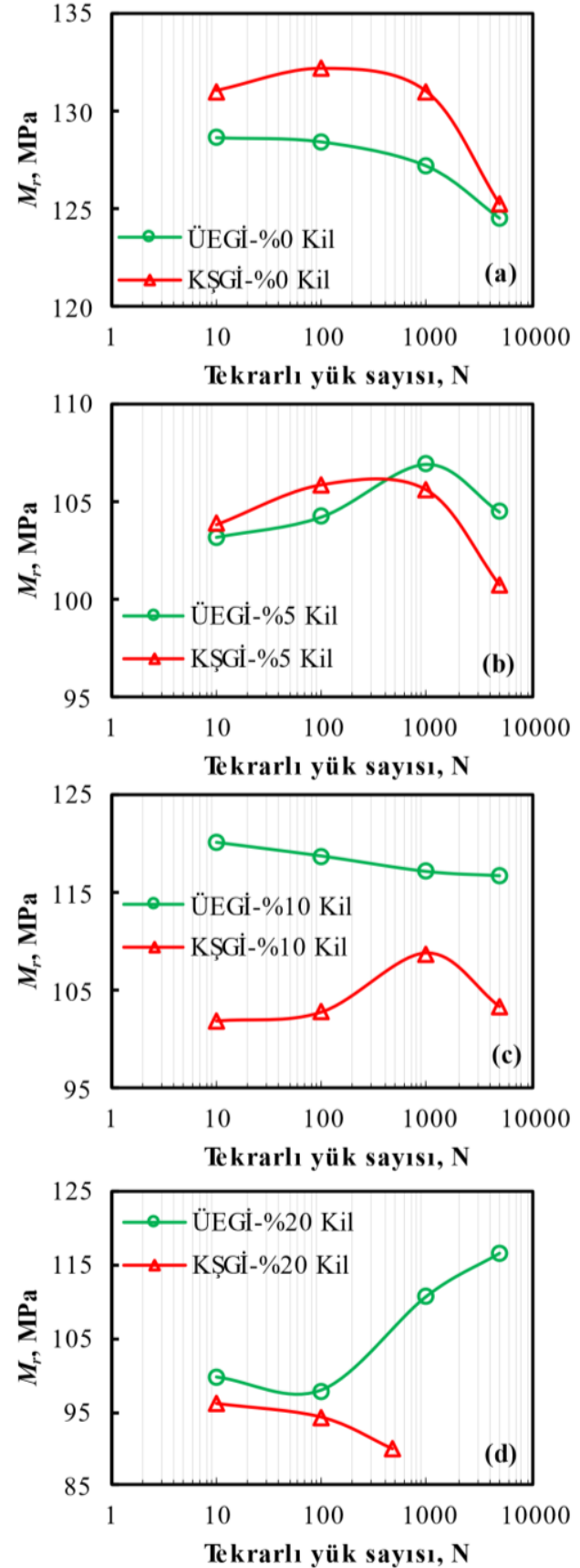

Şekil 4. Esneklik modülünün tekrarlı yükleme sayısı (N), kil içeriği ve gerilme izi ile değişimi

$\% 5$ kil içeren kum-kil numunelerde ise kum numunelerde olduğu gibi 1000 tekrarlı yükleme sayısına kadar esneklik modülü değerlerinde çok az bir değişim olmaktadır ve 1000 tekrarlı yükleme sayısından sonra esneklik modülü değerlerinde meydana gelen azalma KŞGİ altında daha fazla olmaktadır (Şekil 4(b)). Ayrıca 5000 tekrarlı yükleme sayısında \%5 kil içeren kum-kil numunesi KŞGİ altında daha düşük esneklik modülü değeri vermiştir. Tablo 3 'te görüldüğü üzere bu kum-kil numunelerinde meydana gelen şekil değiştirmenin büyük bir kısmı elastik şekil değiştirmedir $\left(\varepsilon_{z}^{r} / \varepsilon_{z}{ }^{t}>88\right)$. Ancak küçük tekrarlı yükleme sayılarında \%5 kil içeren kum-kil numunelerinde KŞGI'den dolayı daha fazla kalıcı şekil değiştirme meydana gelmektedir (Tablo 3 ve Şekil 5(b)). Artan tekrarlı yükleme sayılarında ise KŞGİ'ne maruz kalan numunede meydana gelen elastik eksenel şekil değiştirmenin oranı artmaktadır (Tablo 3). Bu durum kil zeminin KŞGİ altında daha fazla sıkışma davranışı göstermesinden kaynaklanmaktadır. Artan tekrarlı yükleme sayılarında ise bu numune daha stabil bir davranış sergilemektedir (Şekil 5(b)). Şekil 4(b)'ye göre \%5 kil içeren orta-sıkı kum-kil numunelerinin tasarım esneklik modülü belirlenirken tekrarlı yükleme sayısı ve KŞGİ göz önünde bulundurulmalıdır.
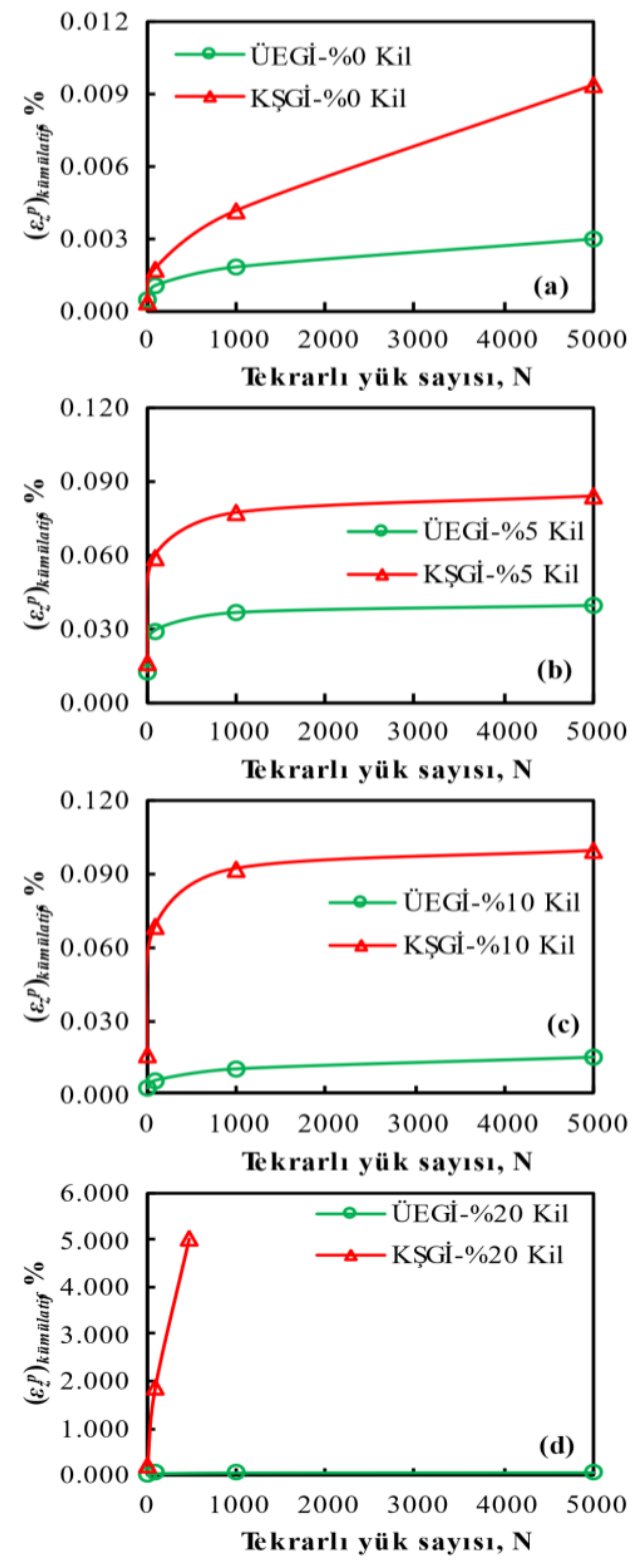

Şekil 5 Farklı tekrarlı yükleme sayılarından (N) sonra kum-kil numunelerinde ölçülen kümülatif kalıcı eksenel şekil değiştirme sonuçlarının $\left(\left(\varepsilon_{z}^{p}\right)_{\text {kümülatif }}\right)$, gerilme izleri (ÜEGİ ve KŞGİ) ve kil içeriği ile değişimi

\%10 kil içeren numunelerde gerilme izinin esneklik modülüne etkisi daha belirgin olmaktadır. Şöyle ki, KŞGİ altında bütün tekrarlı yükleme sayılarında daha düşük esneklik modülü değerleri elde edilmiştir (Şekil 4(c)). Bu 
durum \%10 kil içeren numunede KŞGİ altında daha az eksenel gerilme fark1 ve daha fazla elastik şekil değiştirmenin elde edilmesinden kaynaklanmaktadır (Tablo 3). Ayrıca tekrarlı yükleme sayıları ile esneklik modülünde meydana gelen değişim de bu numunede çok az olmaktadır (Şekil 4(b)). Ancak \%10 kil içeren numune \%5 kil içeren numuneye kıyasla ÜEGİ altında daha fazla esneklik modülü vermektedir (Şekil 4(b) ve 4(c)). Bu durum ise $\% 5$ kil içeren numunede daha az eksenel gerilme farkı ölçülmesine rağmen \%10 kil içeren numunede daha az elastik şekil değiştirmenin meydana gelmesinden kaynaklanmaktadır (Tablo 3). Ayrıca başlangıç tekrarlı yükleme sayılarında KŞGI'ne maruz kalan numunede daha fazla kalıcı şekil değiştirme meydana gelmiştir (Tablo 3). Artan tekrarlı yükleme sayıları ile elastik eksenel şekil değiştirmenin toplam eksenel şekil değiştirmeye oranı da artmakta ve bundan dolayı her iki numune de daha stabil bir eksenel şekil değiştirme davranışı sergilemektedir (Tablo 3 ve Şekil 5(c)). \%10 kil içeren kumkil numunelerinin tasarım esneklik modülü belirlenirken tekrarlı yükleme sayısı ve KŞGİ göz önünde bulundurulmalıdır.

\%20 kil içeren numunelerde, KŞGİ altında daha düşük esneklik modülü elde edilmektedir. Elde edilen esneklik modülü değerleri ise tekrarlı yükleme sayısı ile azalmaktadır. Ancak ÜEGİ'ne maruz kalan numunede, esneklik modülü değerleri artan tekrarlı yükleme sayısı ile artmaktadır (Şekil 4(d)). Bunun nedeni ise bu numunede daha fazla eksenel gerilme farkının ölçülmesidir (Tablo 3). Küçük tekrarlı yükleme sayılarında $(\mathrm{N} \leq 100), \% 20$ kil içeren numuneler her iki gerilme izi altında benzer sonuçlar vermektedir. Bunun nedeni KŞGİ'ne maruz kalan numunede, kalıcı eksenel şekil değiştirmenin daha hızlı gelişmesi ve buna bağlı olarak daha düşük eksenel gerilme farklarının elde edilmesidir (Tablo 3). ÜEGİ altındaki numunede ise eksenel şekil değiştirmenin büyük bir kısmı elastik olarak gerçekleşmektedir $\left(\varepsilon_{z}^{r} / \varepsilon_{z}{ }^{t}>93\right)$. Ancak KŞGİ altındaki numunede ise kalıcı eksenel şekil değiştirme daha fazla gerçekleşmekte ve bundan dolayı düşük tekrarlı yükleme sayılarında göçme meydana gelmektedir (Tablo 3 ve Şekil 5(d)). KŞGİ'ne maruz kalan numunede kalıcı eksenel şekil değiştirmenin hızlı bir şekilde gelişmesi ve buna bağlı olarak göçmenin meydana gelmesi, KŞGİ yükleme koşullarında kritik kil içeriğine sahip olan bu karışımda kum daneleri arasındaki kenetlenmenin olumsuz etkilenmesi ve ince daneli zeminin yük altındaki davranış özelliklerinin bu karışımda daha baskın hale gelmesi ile açıklanabilir. Diğer kil içeriklerinde bu durumun etkisi çok az görülmüştür. Şekil 4(d) ve Şekil 5(d)'ye göre \%20 kil içeren kum-kil karışımlarının esneklik modülü KŞGİ hesaba katılarak belirlenmelidir. Aksi takdirde trafik yüklerinden dolayı yol yapısında meydana gelecek olan eksenel şekil değiştirme davranışı çok daha düşük tahmin edilmektedir.

\section{Sonuçlar}

$\mathrm{Bu}$ çalışmada, ağırlıkça $\% 0, \quad \% 5, \quad \% 10$ ve $\% 20$ oranlarında kil içeren ve tekrarlı trafik yüklerine maruz kalan orta-sıkı kum-kil karışımlarının esneklik modülü parametreleri kalp şekli gerilme izi (KŞGİ) ve üç eksenli gerilme izi (ÜEGİ) ile araştırılmıştır. Bu amaç doğrultusunda, her iki gerilme izi de yarı silindir deney cihazı kullanılarak kum-kil numuneleri üzerinde uygulanmıştır. Kum-kil numuneleri ÜEGİ altında sadece tekrarlı eksenel gerilmeye maruz kalmıştır. Ancak KŞGİ'ne maruz kalan kum-kil numunelerinde ise bu gerilme izini ve asal gerilme dönmesini simüle etmek için tekrarlı eksenel gerilme ve burulmalı kayma gerilmesi aynı anda uygulanmıştır. Elde edilen deney sonuçlarına göre asal gerilme dönmesinin kum zeminin (\%0 kil) esneklik modülü parametresine etkisi çok az olmaktadır. Ayrıca artan tekrarlı yükleme sayısı ile esneklik modülünde azalma meydana geldiği için kum zeminin tasarım esneklik modülü belirlenirken nihai $(\mathrm{N}=5000)$ esneklik modülü değeri kullanılmalıdır. Diğer yandan kum zeminin esneklik modülü artan kil içeriği ile azalmaktadır. Artan kil içeriği ile asal gerilme dönmesinin ve KŞGİ'nin esneklik modülüne etkisi daha belirgin olmaktadır. Şöyle ki, KŞGI'ne maruz kalan ve $\% 5$ 'ten daha fazla kil içeren kum-kil numuneleri daha düşük esneklik modülü değerleri vermiştir. $\mathrm{Bu}$ durum ise bu numunelerde daha fazla kalıcı eksenel şekil değiştirmenin meydana gelmesine sebep olmaktadır. Bundan dolayı ortasıkı kum-kil karışımlarının kullanıldığı yol yapılarının tasarımında tasarım esneklik modülü belirlenirken KŞGİ ve asal gerilme dönmesinin etkileri göz önüne alınmalıdır. Aksi takdirde, elde edilen deney sonuçlarına göre tekrarlı trafik yüklerinden dolayı yol yapılarında meydana gelecek olan kalıcı eksenel şekil değiştirmeler daha düşük tahmin edilmektedir. $\mathrm{Bu}$ durum ise özellikle yol bakım maliyetlerinin önemli miktarda artmasına sebep olabilir.

\section{Teşekkür}

$\mathrm{Bu}$ çalışma, TÜBİTAK yurt dışı doktora sonrası araştırma bursu (2219) ile Iowa Eyalet Üniversitesi İnşaat, Yapı ve Çevre Mühendisliği Bölümü laboratuvarlarında Dr. Cassandra Rutherford ve Doç. Dr. Bora Çetin'in bilgileri dahilinde gerçekleştirilmiştir.

\section{Çıkar çatışması}

$\mathrm{Bu}$ çalışmada, herhangi bir çıkar çatışması bulunmamaktadir.

Benzerlik oranı (iThenticate): $\% 4$

\section{Kaynaklar}

[1] Md. Jibon, D. Mishra and E. Kassem, Laboratory characterization of fine-grained soils for Pavement ME Design implementation in Idaho. Transportation Geotechnics, 25, 100395, 2020. https://doi.org/ 10.1016/j.trgeo.2020.100395.

[2] G. Ma, H. Li, B. Yang, H. Zhang and W. Li, Investigation on the deformation behavior of opengraded unbound granular materials for permeable pavement. Construction and Building Materials, 260, 119800, 2020. https://doi.org/10.1016/j.conbuildmat. 2020.119800 .

[3] L. Guo, Y. Cai, R. J. Jardine, Z. Yang and J. Wang, Undrained behaviour of intact soft clay under cyclic paths that match vehicle loading conditions, Canadian Geotechnical Journal, 55, 90-106, 2018. https://doi.org/10.1139/cgj-2016-0636. 
[4] A. Cetin, Z. Kaya, B. Cetin and A. H. Aydilek, Influence of laboratory compaction method on mechanical and hydraulic characteristics of unbound granular base materials. Road Materials and Pavement Design, 15 (1), 220-235, 2014. https://doi.org/10.1080/ 14680629.2013 .869505$.

[5] I. Haider, Z. Kaya, A. Cetin, M. Hatipoglu, B. Cetin and A. H. Aydilek, Drainage and mechanical behavior of highway base materials. Journal of Irrigation and Drainage Engineering, 140 (6), 04014012, 2014. https://doi.org/10.1061/(ASCE)IR.19434774.0000708.

[6] S. H. He, Z. Ding, T.D. Xia, W. H. Zhou, X. L. Gan, Y. Z. Chen and F. Xia, Long-term behaviour and degradation of calcareous sand under cyclic loading. Engineering Geology, 276, 105756, 2020. https://doi.org/10.1016/j.enggeo.2020.105756.

[7] N. Venkatesh, M. Heeralal and R. J. Pillai, Resilient and permanent deformation behaviour of clayey subgrade soil subjected to repeated load triaxial tests. European Journal of Environmental and Civil Engineering, 24 (9), 1414-1429, 2020. https://doi.org/ 10.1080/ 19648189.2018.1472041.

[8] Y. Cai, Q. Sun, L. Guo, C. H. Juang and J. Wang, Permanent deformation characteristics of saturated sand under cyclic loading. Canadian Geotechnical Journal, 52, 795-807, 2015. https://doi.org/10.1139 /cgj-2014-0341.

[9] L. Guo, J. Chen, J. Wang, Y. Cai and P. Deng, Influences of stress magnitude and loading frequency on cyclic behavior of $K_{0}$-consolidated marine clay involving principal stress rotation. Soil Dynamics and Earthquake Engineering, 84, 94-107, 2016. http://doi.org/10.1016/j.soildyn.2016.01.024.

[10] J. G. Qian, Y. G. Wang, Z. Y. Yin and M. S. Huang, Experimental identification of plastic shakedown behavior of saturated clay subjected to traffic loading with principal stress rotation. Engineering Geology, 214, 29-42, 2016. http://dx.doi.org/10.1016/ j.enggeo.2016.09.012.

[11] Y. Q. Cai, L. Guo, R. J. Jardine, Z. X. Yang and J. Wang, Stress-strain response of soft clay to traffic loading. Géotechnique, 67(5), 446-451, 2017. https://doi.org/ 10.1680/jgeot.15.P.224.

[12] H. I. Fedakar, W. Cai, C. J. Rutherford and B. Cetin, Evaluation of deformation behavior of sand-clay mixture under traffic loads. Geo-Congress 2020, ASCE Geotechnical Special Publications (GSP 317), sayfa 201-209, Minneapolis, Minnesota, ABD, 25-28 Şubat 2020 .

[13] Y. Cai, T. Wu, L. Guo and J. Wang, Stiffness degradation and plastic strain accumulation of clay under cyclic load with principal stress rotation and deviatoric stress variation. Journal of Geotechnical and Geoenvironmental Engineering, 144 (5), 04018021, 2018. https://doi.org/10.1061/(asce)gt.1943-5606. 0001854.

[14] Q. Yang, Y. Tang, B. Yuan and J. Zhou, Cyclic stressstrain behaviour of soft clay under traffic loading through hollow cylinder apparatus: effect of loading frequency. Road Materials and Pavement Design, 20 (5), 1026-1058, 2019. https://doi.org/10.1080/ 14680629.2018 .1428219$.

[15] D. C. Simpson and T. M. Evans, Behavioral thresholds in mixtures of sand and kaolinite clay. Journal of Geotechnical and Geoenvironmental Engineering, 142 (2), 04015073, 2016. https://doi.org/10.1061/ (ASCE)GT.1943-5606.0001391.

[16] H. Choo, W. Lee and C. Lee, Compressibility and small strain stiffness of kaolin clay mixed with varying amounts of sand. KSCE Journal of Civil Engineering, 21 (6), 2152-2161, 2017. https://doi.org/10.1007/ s12205-016-1787-4.

[17] M. Cubrinovski and S. Rees, Effects of fines on undrained behaviour of sands. Geotechnical Earthquake Engineering and Soil Dynamics IV, ASCE Geotechnical Special Publications (GSP 181), sayfa 111, Sacramento, California, ABD, 18-22 May1s 2008.

[18] P. V. Lade, C. D. Liggio and J. A. Yamamuro, Effects of non-plastic fines on minimum and maximum void ratios of sand. ASTM Geotechnical Testing Journal, 21 (4), 336-347, 1998. https://doi.org/10.1520/ GTJ11373J.

[19] A. Miftah, A. H. B. Garoushi and H. Bilsel, Effects of fine content on undrained shear response of sand-clay mixture. International Journal of Geosynthetics and Ground Engineering, 6 (10), 2020. https://doi.org/ 10.1007/s40891-020-0193-7.

[20] B. M. Das, Principles of Geotechnical Engineering. Cengage Learning, CT, ABD, 2010.

[21] C. Chazallon, P. Hornych and S. Mouhoubi, Elastoplastic model fort he long-term behavior modeling of unbound granular materials in flexible pavements. International Journal of Geomechanics, 6 (4), 279-289, 2006. https://doi.org/10.1061/(asce) 1532-3641(2006)6:4(279). 